\title{
Dead sea climatotherapy for psoriasis vulgaris: analysis of short-term results
}

\author{
Marco Harari ${ }^{1,2,3 *}$, Yaron Sela ${ }^{4}$, Arieh Ingber ${ }^{5}$ and Daniel Vardy ${ }^{3}$ \\ ${ }^{1} \mathrm{DMZ}$ Medical Center, Lot Spa Hotel, Dead Sea, Israel \\ ${ }^{2}$ Dead Sea \& Arava Science Center, Israel \\ ${ }^{3}$ Department of Dermatology, Soroka Medical Center, Ben Gurion University, Beer Sheva, Israel \\ ${ }^{4} \mathrm{P}$ Value Ltd., Research and Statistics, Israel \\ ${ }^{5}$ Department of Dermatology, Hadassah Hospital, Hebrew University, Jerusalem, Israel
}

\begin{abstract}
Background: Psoriasis is a common skin disease which beneficiated lately from many new drugs, acting on immunity. Phototherapy remains however a cornerstone of treatment in moderate-to-severe forms. Patients exhibit a continuous and longstanding interest in Dead Sea Climatotherapy (DSC), a well-known off-label psoriasis treatment which demonstrated high rates of success since decades.

Objective: We sought to determine the success rates of DSC and to compare the populations of patients reaching different levels of clearance, in order to correlate results with their respective demographic and clinical variables. We also compare two different criteria of evaluation based on the Psoriasis Area and Severity Index: PASI 75 and PASI 90.

Patients and methods: Files of 790 patients suffering from moderate-to-severe Psoriasis vulgaris, who underwent DSC at the Deutsches Medizinisches Zentrum (DMZ) during the past five years were automatically retrieved if PASI at arrival was above 10 and included in this statistical study. In the group of patients who reached $75 \%$ and more improvement of PASI ( $n=719)$, PASI improvement (PASI\%) was first evaluated as a dichotomous variable, as patients were divided in two groups: PASI 75-90 and PASI 90, and secondly was considered as a continuous variable.

Results: PASI 75 and PASI 90 reached respectively 91\% and 76.8\%. Previous treatment at the Dead Sea significantly predicted PASI 90, and age of onset of disease was found inversely correlated to better results. Photo skin type II was found to significantly correlate to PASI 90.

Conclusion: Climatotherapy was confirmed as a successful therapy for almost any plaque psoriasis patient. No essential differences were found between patients reaching PASI 75 or PASI 90. PASI 90 seems to be of better value by evaluating immediate results in modern therapeutic trials, while allowing a better therapeutic choice for a specific patient.
\end{abstract}

\section{Introduction}

Dead Sea Climatotherapy is known for the treatment of psoriasis since more than forty years, with first publications appearing sporadically in the late 70 s of the past century [1]. Since, a lot of clinical studies confirmed the spectacular success of the treatment, while reporting its effect of thousands of European sufferers treated in clinics flourishing in Ein Bokek, at the Dead Sea [2,3]. Explanations on the mechanism involved were proposed later on, and were many times exposed, mainly by the team of Kudish [4].

One of these first publications [5] tried to objective which patients can better beneficiate from the sun exposure and the Dead Sea bathes proposed daily, under medical supervision, during 3 weeks or more. More recently, psoriasis at earlier age, which is usually correlated to poor results, was found to be slightly better improved than psoriasis emerging later in life [6]. Thus, it seems important to define which patients hold the best chances to reach total or almost-total clearance through this natural method of treatment, which was demonstrated as free of side effects [7], well accepted and improving largely Quality of Life parameters [8].

PASI (Psoriasis Area Severity Index) is commonly used to quantify psoriasis with an absolute number as a follow-up measure. As an outcome measure in therapeutic trials, PASI is represented as PASI 50, PASI 75, PASI 90 or PASI 100. PASI 90, for example, represents the percentage (or number) of patients who have achieved a $90 \%$ or more reduction in their PASI score from the baseline value. Lately PASI 90 has gained more importance over PASI 75, as it correlates better with health-related quality of life measurements and because of the availability of much more potent treatments.

\section{Patients and methods}

We examined the records of the patients suffering from Psoriasis vulgaris, who underwent 3 or 4 weeks of DSC in the past 5 years at the DMZ. 790 patients were automatically selected if their PASI at arrival was higher than 10. As a routine, PASI evaluation for each patient is regularly done immediately before treatment, at arrival at the Dead Sea, and after completion of DSC, by the same dermatologist. Details of the

Correspondence to: Marco Harari, DMZ Medical Center, Lot Spa Hotel, Dead Sea, Israel; E-mail: marco.harari@gmail.com

Received: March 28, 2016; Accepted: May 03, 2016; Published: May 06, 2016 
individual program administered to the patients were already exposed and discussed in previous publications $[2,4]$.

This study was approved by the ethics committee of the RIDS, Research Institute on Skin Diseases at the Dead Sea. All patients signed an informed consent when entering the clinic and accepted the use of their anonymous data for scientific research.

In the records examined, we found that 719 patients (91\%) reached PASI improvement of $75 \%$ and we choose them as our study population. $70.2 \%$ were males, $78.1 \%$ were with skin photo type III (following Fitzpatrick classification) and the means of age and Body Mass Index reached respectively 51.2 years and $28.8 \mathrm{Kg} / \mathrm{s}-\mathrm{m}$.

The demographic variables distributions are presented in Table 1. The PASI values before and after treatment distributions are presented in Table 2. The clinical and treatment variables distributions are presented in Table 3.

\section{Results}

This statistical retrospective cohort study aimed to assess the results of Dead Sea Climatotherapy (DSC) given at the Deutsches
Medizinisches Zentrum (DMZ) by several analysis of the Psoriasis Assessment of Severity Index (PASI) recorded before and after treatment while trying to find clinical parameters that predict the PASI improvement (PASI\%).

From the 790 files of patients included in this study (with an initial PASI reaching at least the value of 10 ), $91 \%$ reached PASI 75 , and $76.8 \%$ reached PASI 90. As seen in Table 2, the mean PASI at arrival for patients reaching PASI $75(\mathrm{n}=719)$ dropped from 19.93 to 0.79 , defining a mean improvement, after 28 days of treatment, of $96 \%$.

- Previous treatments at the Dead Sea were found to be a positive predictor for a better PASI\%, as patients who underwent more DSC in the past had higher chances to reach PASI 90: the more DSC the patient underwent in the past, the higher PASI\% that was reached.

- A positive association was found between the length of the disease, in years, and PASI\%: the longer the patient suffered from psoriasis the higher were the chances to reach PASI 90.

- A negative association was found between PASI\% and age at onset of disease: patients who started earlier in life their diseases were more likely to reach PASI 90.

Table 1. Demographic distributions.

\begin{tabular}{|c|c|c|c|c|c|c|}
\hline Variable & Category & $\mathbf{N}$ & $\%$ & Range & M & SD \\
\hline \multirow[t]{2}{*}{ Gender } & Males & 505 & 70.2 & & & \\
\hline & Females & 214 & 29.8 & & & \\
\hline \multirow[t]{4}{*}{ Skin type } & 2 & 138 & 19.3 & & & \\
\hline & 3 & 562 & 78.6 & & & \\
\hline & 4 & 13 & 1.8 & & & \\
\hline & 5 & 2 & 0.3 & & & \\
\hline \multicolumn{2}{|c|}{ Age } & & & $10-87$ & 51.24 & 12.6 \\
\hline \multicolumn{2}{|c|}{ BMI } & & & $17-61$ & 28.86 & 5.30 \\
\hline
\end{tabular}

( $\mathrm{N}=$ number of patients; $\%=$ percentage; $\mathrm{M}=$ mean; $\mathrm{SD}=$ standard deviation).

Table 2. Descriptive statistics for PASI before and after DSC for all patients and for the 2 sub-groups PASI 75-90 and PASI 90. PASI Improvement $=[($ Before - After $) /$ Before $]$.

\begin{tabular}{|c|c|c|c|c|c|c|c|}
\hline \multicolumn{2}{|c|}{ Populations } & \multicolumn{2}{|c|}{ PASI Before DSC } & \multicolumn{2}{|c|}{ PASI After DSC } & PASI Improvement (\%) \\
\hline & N & M & SD & M & M & 1.49 \\
\hline ALL & 719 & 19.93 & 8.85 & 0.79 & 96.3 \\
\hline PASI 75-90 & 117 & 21.65 & 10.13 & 3.39 & 2.05 \\
\hline PASI 90 & 602 & 19.60 & 8.55 & 0.29 & 0.54 \\
\hline
\end{tabular}

( $\mathrm{N}=$ number of patients; \%=percentage; $\mathrm{M}=$ mean; $\mathrm{SD}=$ standard deviation).

Table 3. Clinical and treatment variables distributions.

\begin{tabular}{|c|c|c|c|c|c|c|c|}
\hline Variable & Category & $\mathbf{N}$ & $\%$ & Range & Unit & $\mathbf{M}$ & SD \\
\hline \multirow[t]{2}{*}{ Family history of psoriasis } & No background & 335 & 50.9 & \multirow[t]{2}{*}{$0-1$} & \multirow[t]{2}{*}{-} & \multirow[t]{2}{*}{0.49} & \multirow[t]{2}{*}{0.50} \\
\hline & With background & 323 & 49.1 & & & & \\
\hline \multirow[t]{2}{*}{ Systemic treatment in the past } & No & 480 & 83.8 & \multirow[t]{2}{*}{$0-1$} & \multirow[t]{2}{*}{-} & \multirow[t]{2}{*}{0.16} & \multirow[t]{2}{*}{0.37} \\
\hline & Yes & 15 & 21.1 & & & & \\
\hline \multicolumn{2}{|l|}{ Previous DSC treatments } & 719 & & $0-37$ & - & 6.91 & 7.90 \\
\hline \multicolumn{2}{|l|}{ Age at disease onset } & 719 & & $0-76$ & Years & 22.92 & 12.54 \\
\hline \multicolumn{2}{|c|}{ Disease duration (Age of the disease) } & 719 & & $0-81$ & Years & 28.01 & 13.24 \\
\hline \multicolumn{2}{|l|}{ Body surface involvement } & 719 & & $3-100$ & Percent & 45.13 & 20.30 \\
\hline \multicolumn{2}{|c|}{ Sun exposure reached (patient daily log) } & 719 & & $350-8640$ & $\begin{array}{l}\text { Milli Joules per } \\
\text { square centimeters }\end{array}$ & 3073.42 & 1089.46 \\
\hline
\end{tabular}

( $\mathrm{N}=$ number of patients; $\%=$ percentage; $\mathrm{M}=$ mean; $\mathrm{SD}=$ standard deviation). 
- More patients with photo skin type II (Fitzpatrick) than others reached PASI 90.

No significant associations were found between PASI\% and age, gender, duration of treatment, Body Mass Index, skin involvement, PASI at arrival and dose of sun exposure received.

Thus, only small differences were found in this study between the two ways of evaluation, using either PASI 75 or PASI 90.

In order to examine the association between clinical measures and PASI\%, this outcome was evaluated by three different methods.

A. The first method was calculating by PASI\% as a dichotomous variable as patients were divided into 2 groups: patients with $75-90 \%$ of PASI improvement and patients reaching $90.1-100 \%$ improvement in their PASI evaluation.

B. The second method calculated PASI\% measure as a continuous variable.

C. The third method calculated PASI\% as an overlapping dichotomous measure: patients with $75-100 \%$ improvement of PASI versus patients with $90-100 \%$ of PASI improvement.

\section{A. PASI\% as a dichotomous measure (75-90 versus 90.1-100)}

The Table 4 presents the differences between PASI groups for demographic and clinical measures.

As can be seen in Table 4, significant difference was found with the "previous DSC treatment" variable $(\mathrm{T}(695)=3.722, \mathrm{p}=.000)$, meaning, people who had better PASI\% were those who underwent more DSC treatments in the past. Furthermore, significant effect was also found with the "skin type" variable $\left(\mathrm{X}^{2}=11.167, \mathrm{p}=.011\right)$, while larger percentage of patients with photo skin type II was found in the 90-100 group in comparison to the 75-90 group. Finally, significant effect was found with the "duration of disease" (or "age of the disease") variable $(\mathrm{T}(717)=2.293, \mathrm{p}=.022)$. People who suffered from the disease more years were more likely to reach PASI 90. As for the other variables, none was found to be significant.

In order to examine which clinical measures significantly predicted PASI\%, logistic regression analysis was applied. Gender and age were controlled for while the clinical measures entered the model as independent measures. The dependent measure was PASI\%. The following table presents the results.

The model presented in Table 5 successfully classified $84.3 \%$ of cases. Additionally, the model explained $7.7 \%$ of PASI\%'s variance $\left(\mathrm{X}^{2}=19.889, \mathrm{p}=.047\right)$.

Specifically, previous treatment significantly predicted PASI $(\mathrm{OR}=1.07,95 \% \mathrm{CI}=1.018-1.122, \mathrm{p}=.007)$. Meaning, patient who underwent DSC in the past had 7\% more chances to show $90.1-100 \%$ PASI improvement. Other variables had no significant associations with PASI\%.

\section{B. PASI Improvement (PASI\%) as a continuous measure}

In order to examine associations between PASI\% and demographic and clinical measures, we sought first to represent the PASI\% distribution, when plotted against different variables. Graph 1 shows the lack of differences between the different sub groups of patients and the Graphs 2-7 allows a vision of the PASI\% distribution for the whole population, as regards to many variables.

A few t-tests for independent samples were conducted and a correlations matrix was calculated. The following Tables 6 and 7 present the associations found.

As seen in Tables 6 and 7, only 3 measures were associated with PASI\%. Previous treatments at the Dead Sea were positively

Table 4. Differences between PASI\% groups for demographic and clinical measures.

\begin{tabular}{|c|c|c|c|c|c|c|}
\hline & \multirow[t]{2}{*}{ Variable (Unit) } & \multicolumn{2}{|c|}{$75-90 \%$ PASI } & \multicolumn{2}{|c|}{$90.1-100 \%$ PASI } & \multirow[t]{2}{*}{ Difference } \\
\hline & & N (\%) & $\mathrm{M}(\mathrm{SD})$ & N (\%) & $\mathrm{M}(\mathrm{SD})$ & \\
\hline & Gender & & & & & $X^{2}=0.068, p=.795$ \\
\hline$\bullet$ & Males & $81(69.2)$ & & $424(70.4)$ & & \\
\hline$\bullet$ & Females & $36(30.8)$ & & $178(29.6)$ & & \\
\hline & Skin type & & & & & $X^{2}=11.167, p=.011$ \\
\hline$\bullet$ & 2 & $20(17.4)$ & & $118(19.7)$ & & \\
\hline$\bullet$ & 3 & $90(78.3)$ & & $472(78.7)$ & & \\
\hline$\bullet$ & 4 & $3(2.6)$ & & $10(1.7)$ & & \\
\hline$\bullet$ & 5 & $2(1.7)$ & & $0(0)$ & & \\
\hline & Family history & & & & & $X^{2}=1.604, p=.205$ \\
\hline$\bullet$ & No & $61(56.5)$ & & $274(49.8)$ & & \\
\hline$\bullet$ & Yes & $47(43.5)$ & & $276(50.2)$ & & \\
\hline & Systemic in the past & & & & & $\mathrm{X}^{2}=0.030, \mathrm{p}=.862$ \\
\hline$\bullet$ & No & $74(83.1)$ & & $406(83.9)$ & & \\
\hline$\bullet$ & Yes & $15(16.9)$ & & $78(16.1)$ & & \\
\hline & Previous DSC & & $4.75(6.58)$ & & $7.34(8.07)$ & $T=3.722, p=.000$ \\
\hline & Age (Years) & & $50.80(13.87)$ & & $51.33(12.35)$ & $\mathrm{T}=0.387, \mathrm{p}=.700$ \\
\hline & Days of treatment & & $27.77(7.13)$ & & $28.08(6.93)$ & $\mathrm{T}=0.446, \mathrm{p}=.656$ \\
\hline & $\begin{array}{l}\text { Age at disease onset } \\
\text { (Years) }\end{array}$ & & $25.07(14.30)$ & & $22.51(12.13)$ & $\mathrm{T}=1.807, \mathrm{p}=.073$ \\
\hline & $\begin{array}{l}\text { Disease duration } \\
\text { (Years) }\end{array}$ & & $25.45(14.08)$ & & $28.51(13.03)$ & $\mathrm{T}=2.293, \mathrm{p}=.022$ \\
\hline & $\begin{array}{l}\text { Body surface } \\
\text { involvement (\%) }\end{array}$ & & $44.74(20.47)$ & & $45.21(20.29)$ & $\mathrm{T}=0.228, \mathrm{p}=.820$ \\
\hline & Sun exposure $\left(\mathrm{Mjcm}^{2}\right)$ & & $3102.72(1271.46)$ & & $3067.93(1053.34)$ & $\mathrm{T}=0.244, \mathrm{p}=.807$ \\
\hline
\end{tabular}


Table 5. Logistic regression for PASI\% prediction by the clinical variables.

\begin{tabular}{|l|c|c|c|}
\hline \multicolumn{1}{|c|}{ Variable } & Odds Ratio & $\begin{array}{c}\text { Lower limit } \\
\text { of C.I. (95\%) }\end{array}$ & $\begin{array}{c}\text { Upper } \\
\text { limit of } \\
\text { C.I. (95\%) }\end{array}$ \\
\hline Gender (0-Males, 1-Females) & 0.93 & 0.50 & 1.70 \\
\hline Age & 0.60 & 0.24 & 1.49 \\
\hline Previous DSC treatment & $\mathbf{1 . 0 7 * *}$ & 1.02 & 1.12 \\
\hline Days of treatment & 1.04 & 0.98 & 1.10 \\
\hline Age at disease onset & 1.64 & 0.66 & 4.05 \\
\hline Disease duration & 1.68 & 0.68 & 4.15 \\
\hline Body surface involvement & 1.00 & 0.98 & 1.01 \\
\hline Sun exposure (Mjcm $\left.{ }^{2}\right)$ & 1.00 & 1.00 & 1.00 \\
\hline Systemic treatment in the past (0-no, 1-yes) & 0.80 & 0.40 & 1.60 \\
\hline Family history (0-no, 1-yes) & 1.01 & 0.57 & 1.78 \\
\hline Skin type (0-other, 1-3) & 1.06 & 0.43 & 2.64 \\
\hline
\end{tabular}

$*_{p}<.05, * *_{p}<.01$

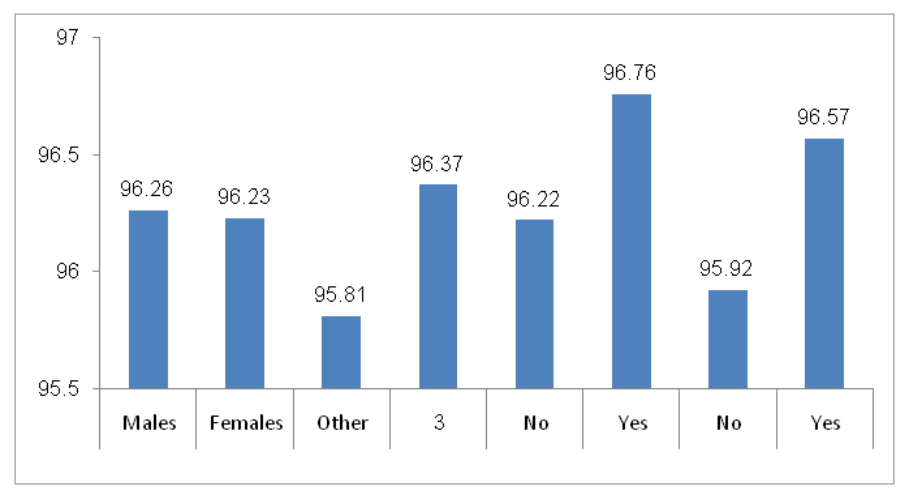

Graph 1. Categorical clinical and demographic measures and PASI $\%$.

related to PASI improvement. Meaning, the more previous Dead Sea Climatotherapy the patient underwent, the higher PASI improvement was at the current one. Additionally, age at disease onset was negatively related to PASI\%. Namely, the older the patient was at the onset of the disease, the lower PASI improvement was. Finally, duration of the disease was found as positively related to PASI\%: the longer the patient suffered from the disease, the higher were the chances to reach greater PASI\%.

In order to examine which clinical measures significantly predicted PASI\%, regression analysis was applied. Gender was controlled for while the clinical measures entered the model as independent measures. The dependent measure was PASI\%. Age did not enter the regression due to co-linearity with the other measures containing age component. The Table 8 presents the results.

As seen in the table, the model explained $5.7 \%$ of PASI's variance $(\mathrm{F}=2.836, \mathrm{p}=.003)$. The only significant measure was previous treatment, as it had positively predicted PASI: the more previous climatotherapy at the Dead Sea the patient underwent, the higher was the PASI at the end of the current treatment.

\section{PASI as a dichotomous overlapping measure $(75-100 \%$ versus 90-100\% in PASI Improvement)}

Even if not logically acceptable, we run some tests between two overlapping groups of patients - those who, after DSC, reached more than $75 \%$ improvement and those who obtained PASI\% more than $90 \%$. The Table 9 presents the differences between these groups of patients (the first one being including the second one), regarding their demographic and clinical variables.
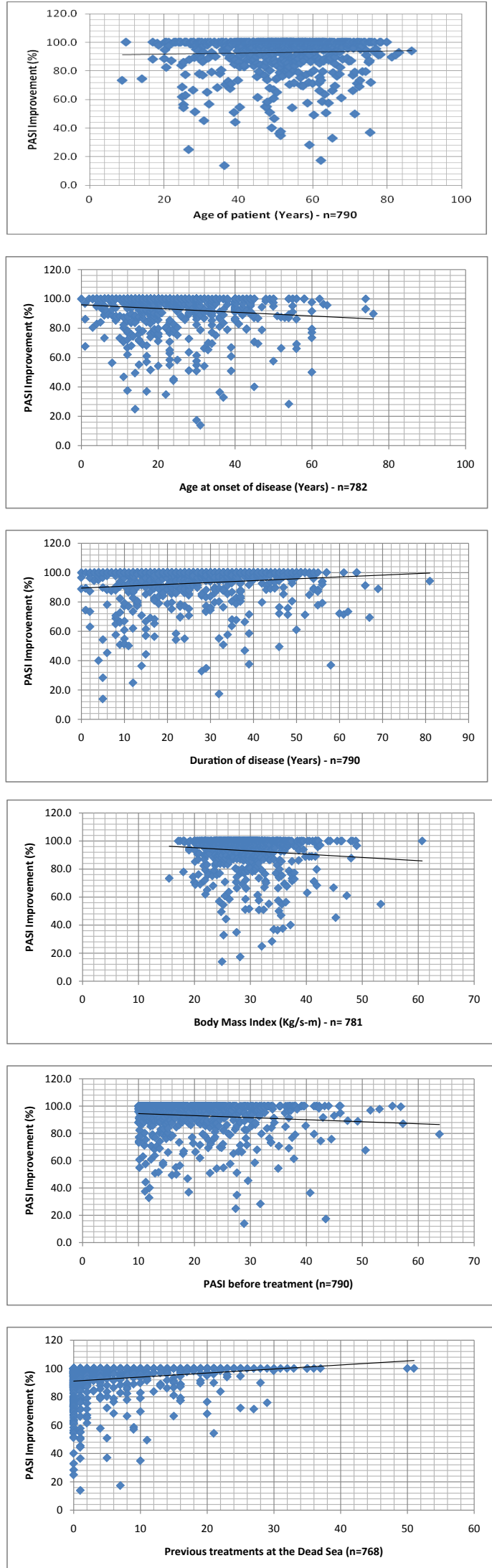

Graphs 2-7. PASI Improvement distribution, related to age of patient, age at onset of disease, age of disease, Body Mass Index, PASI before treatment and number of previous treatments at the Dead Sea. 
Table 6. Differences between categorical clinical and demographic measures and PASI\%.

\begin{tabular}{|l|c|c|c|c|}
\hline \multicolumn{1}{|c|}{ Variable } & Levels & N & Mean & Difference \\
\hline Gender & Males & 505 & 96.26 & \multicolumn{1}{|c|}{$\mathrm{T}=0.069, \mathrm{p}=.945$} \\
\hline Skin type & Females & 214 & 96.23 & 6 \\
\hline & Other & 157 & 95.81 & 6.35 \\
\hline Systemic treatment in the past & 3 & 562 & 96.37 & 5.81 \\
\hline & No & 480 & 96.22 & 5.99 \\
\hline Family history & Yes & 93 & 96.76 & 5.74 \\
\hline & No & 335 & 95.92 & 6.22 \\
\hline
\end{tabular}

Table 7. Pearson correlations between PASI $\%$ and clinical and demographic measures.

\begin{tabular}{|l|c|}
\hline Variable & PASI\% \\
\hline Previous DSC treatment & $\mathbf{. 1 6 8}^{\text {*** }}$ \\
\hline Age & -.008 \\
\hline Days of treatment & .031 \\
\hline Age at disease onset & $\mathbf{- . 1 1 8 ^ { * * }}$ \\
\hline Disease duration & $\mathbf{. 0 9 9}^{\text {**k }}$ \\
\hline Body surface involvement & .022 \\
\hline Sun exposure & .053 \\
\hline
\end{tabular}

$*_{p}<.05, * * p<.01$

Table 8. Regression for PASI\% prediction by the clinical variables.

\begin{tabular}{|l|l|c|c|}
\hline Step & Variable & B & $\mathbf{R}^{2}$ change \\
\hline $\mathbf{1}$ & Gender (0-Male,1-Female) & .017 & 0.002 \\
\hline $\mathbf{2}$ & Previous DSC treatment & $\mathbf{. 2 0 1}$ & $\mathbf{. 0 5}^{* *}$ \\
\hline & Days of treatment & .064 & \\
\hline & Age at disease onset & -.090 & \\
\hline & Duration of disease & .024 & \\
\hline & Body surface involvement & -.020 & \\
\hline & Sun exposure (Mjcm2) & -.088 & \\
\hline & Systemic treatment in the past (0-no,1-yes) & .001 & \\
\hline & Family history (0-no,1-yes) & .013 & \\
\hline & Skin type (0-other,1-3) & -.004 & \\
\hline & $* p<.05, * * p<.01$ & & \\
\hline
\end{tabular}

As seen in Table 9, no significant difference was found between these two groups for any clinical or demographic measures.

In order to examine whether clinical variables significantly predicted PASI\%, logistic regression analysis was applied. Gender and age were controlled for while the clinical measures entered the model as independent measures. The dependent measure was PASI\%. None of the suggested predictors was significant. Furthermore, the model did not explain variance in PASI\% $\left(\mathrm{X}^{2}=1.425, \mathrm{p}=1\right)$. No significant associations were found between independent variables and PASI value.

\section{Discussion}

This statistical study reaffirms once more the high success rates of DSC for psoriasis and demonstrates some associations with clinical and demographic variables [2]. Comparison of the two sub-populations which reached respectively 75 to $90 \%$ and 90 to $100 \%$ improvement in PASI improvement did not reveal many differences except for these variables: previous treatments at the Dead Sea, age at onset of disease, duration of disease and photo skin type II.

DSC seems to be a very effective therapeutic option and its efficacy does not depend of any demographic or clinical data. PASI 75,90 and 100 reached respectively and $91 \%, 76.8 \%$ and $50.6 \%$ after a 4-week treatment, values that confirm the high success rates of this method. Mean absolute PASI at end reached $0.79 \pm 1.49$ and Quality of Life parameters were in parallel greatly improved (data not shown), comforting results reported in previous publications [3]. There is no evidence for suggesting a need to reconsider such a treatment on the basis of the patient' age, gender, skin involvement severity, Body Mass Index, and neither severity of disease (if considering the PASI at arrival). In another hand, previous Dead Sea treatments enhance the chances of better results, as do the fact that patient has a disease since a long while, or since an early age. As well, the photo skin type II - but not the total amount of sun exposure received during treatment - was found as a predictor of PASI 90 in this study.

These results necessitate some explanations, even if there show only modest significance. Indeed, if it seems quite normal that patients with greater experience at the Dead Sea reach better results, one cannot easily understand why repetitive natural phototherapy does not induce lower success rates, and, in the contrary, improves the treatment outcomes. As well, early onset has been always considered as a handicap for the patients, being suffering from a more aggressive form of the disease, and not as an advantage. Finally, one should understand why patients with photo skin type II showed better results.

In fact, we believe that some answers can be found in the essence of Dead Sea Climatotherapy, and in the many ways that this unique treatment act on the patients and on their disease. This natural selective phototherapy in the Ultra Violet (UV) B ranges cannot be compared to the artificial ones, even not to home phototherapy. At the Dead Sea, the daily exposures to the sun, strictly medically controlled, deliver a more intense modulation of the immune system, being possible because of the lower intensities of UVB present. Therefore one can reach a total skin clearance more rapidly than in classical phototherapy, stop earlier the treatment, and so prevent the weakness of repetitive therapy.

Balneotherapy has been shown as an effective additional therapy when coupled to artificial phototherapy [9]. At the Dead Sea, bathes in the salty water are also positively influencing the results obtained [10], but the mechanism involved is still not totally understood.

Moreover, patients at the Dead Sea reported a real sensation of well-being and many of their psychological difficulties are improved, through exchanges, discussions and social activities with counterparts. Patients are often awaiting their Dead Sea treatment in order to "recharge their batteries" and spare energy for the rest of the year. They leave the clinic with a true sensation of health and recovery from their chronic disease. These achievements cannot be compared to those obtained by artificial phototherapy, and maybe even not with the ones reached by biologicals.

Based on these observations, one can explain our results as a consequence of a more effective treatment, involving many aspects of the management of this chronic disease and acting on many levels. 
Table 9. Differences between PASI\% groups (demographic and clinical variables).

\begin{tabular}{|c|c|c|c|c|c|c|}
\hline & \multirow[t]{2}{*}{ Variable } & \multicolumn{2}{|c|}{$75-100 \%$ PASI } & \multicolumn{2}{|c|}{$90-100 \%$ PASI } & \multirow[t]{2}{*}{ Difference } \\
\hline & & $\mathrm{N}(\%)$ & $\mathrm{M}(\mathrm{SD})$ & $\mathrm{N}(\%)$ & $\mathrm{M}(\mathrm{SD})$ & \\
\hline & Gender & & & & & $\mathrm{X}^{2}=0.018, \mathrm{p}=.892$ \\
\hline$\bullet$ & Males & $505(70.2)$ & & $427(70.6)$ & & \\
\hline$\bullet$ & Females & $214(29.8)$ & & $178(29.4)$ & & \\
\hline & Skin type & & & & & $\mathrm{X}^{2}=1.748, \mathrm{p}=.626$ \\
\hline$\bullet$ & 2 & $138(19.3)$ & & $118(19.6)$ & & \\
\hline$\bullet$ & 3 & $562(78.6)$ & & $475(78.8)$ & & \\
\hline$\bullet$ & 4 & $13(1.8)$ & & $10(1.7)$ & & \\
\hline$\bullet$ & 5 & $2(0.3)$ & & $0(0)$ & & \\
\hline & Family history & & & & & $\mathrm{X}^{2}=0.168, \mathrm{p}=.682$ \\
\hline$\bullet$ & No & $335(50.9)$ & & $275(49.7)$ & & \\
\hline$\bullet$ & Yes & $323(49.1)$ & & $278(50.3)$ & & \\
\hline & Systemic treatment in the past & & & & & $\mathrm{X}^{2}=0.009, \mathrm{p}=.925$ \\
\hline$\bullet$ & No & $480(83.8)$ & & $409(84)$ & & \\
\hline$\bullet$ & Yes & $93(16.2)$ & & $78(16)$ & & \\
\hline & Previous DSC treatment & & $6.91(7.90)$ & & $7.34(8.06)$ & $\mathrm{T}=0.946, \mathrm{p}=.344$ \\
\hline & Age (Years) & & $51.24(12.60)$ & & $51.29(12.34)$ & $\mathrm{T}=0.074, \mathrm{p}=.941$ \\
\hline & Days of treatment & & $28.03(6.96)$ & & $28.08(6.91)$ & $\mathrm{T}=0.128, \mathrm{p}=.898$ \\
\hline & Age at disease onset (Years) & & $22.92(12.53)$ & & $22.52(12.11)$ & $\mathrm{T}=0.596, \mathrm{p}=.551$ \\
\hline & Disease duration (Years) & & $28.01(13.24)$ & & $28.46(13.02)$ & $\mathrm{T}=0.621, \mathrm{p}=.534$ \\
\hline & Body surface involvement (\%) & & $45.13(20.30)$ & & $45.12(20.29)$ & $\mathrm{T}=0.012, \mathrm{p}=.990$ \\
\hline & Sun exposure $\left(\mathrm{Mjcm}^{2}\right)$ & & $3073.42(1089.46)$ & & $3070.90(1054.31)$ & $\mathrm{T}=0.038, \mathrm{p}=.970$ \\
\hline
\end{tabular}

Noteworthy, the three parameters that better correlate PASI 90 do not correspond to the disease severity, but rather to the chronicity of the psoriasis. Indeed, patients with numerous previous treatments at the Dead Sea and an early age at onset of disease can be classified as more chronic sufferers. Thus, it seems that Dead Sea Climatotherapy is more adapted for these patients, because of the availability of multi-factorial approaches of both disease and patient.

On the base of the results of this study, one should recommend with more enthusiasm DSC to patients with skin type II, who were already treated at the Dead Sea, and who had an early onset (and a long history) of their disease. But this therapy should be considered as well for all patients suffering from moderate-to-severe disease.

Comparison of success rates between DSC and new biologics therapies is far beyond the scope of this study. However, one can easily align the results of the natural balneo-phototherapy to the best outcomes of the latest studies. Comparing PASI 90 and PASI 100, at 4 week for DSC and 16 weeks for Etanercept, Secukinumab and Ustekinumab will give such values: $76.8 \% / 31.3 \% / 57.6 \% / 79 \%$ for PASI 90 and 50.6\%/7.4\%/28.4\%/44.3\% for PASI 100, respectively [11].

Most patients with Psoriasis would like to achieve complete clearance of their lesions, and do not care of (only) a 75\% improvement. Indeed, it seems difficult to talk about success when the absolute PASI value is above 5, for those patients with baseline PASI over 20 [12]. In our experience, many patients with PASI around 5 showed a substantial impairment in their Quality of Life (QoL) evaluations, even with such a value (data not shown).

The considerable social and psychological burden of the lesions, which greatly affect QoL parameters, cannot be improved significantly without reaching near clearance, as already demonstrated in clinical studies. Therefore it seems logical to encourage the use of PASI 90 in therapeutic trials, as some authors already did, among the absolute PASI value reached and QoL evaluations [13].
Finally, one should better understand the reasons of not reaching complete clearance or near complete clearance, through seeking possible significant correlations between patient's characteristics and results. PASI 90 evaluation should help us in this way, and better define therapeutic success. Still, in the era of potent and "successful" therapies, we should ask ourselves why only $50 \%$ of the patients (in the best scenario, using biologicals or the Dead Sea) are totally cleared after treatment.

Limitations of this study are obvious. We are not dealing with a randomized controlled clinical trial but only with a retrospective statistical analysis of a population of patients which was "selected" simply by the fact that they underwent a treatment at the Dead Sea. Nevertheless, we believe that the goals we fixed were reached and our conclusions might be accepted, even without fitting the well-known criteria of evidence based medicine.

\section{Conclusions}

Dead Sea Climatotherapy represents a valuable option for moderate-to-severe psoriasis vulgaris, at least when considering the results after treatment. The population of patients reaching PASI 75 but not PASI 90 and the one including patients reaching PASI 90 were found very similar in this statistical study, except for some clinical variables related to the disease and the patient history.

However, such a finding should not grant any advantage to the old gold standard PASI 75. In the contrary, we believe that PASI 90 should become soon the best and only way to evaluate results of clinical studies, especially when high success rates are expected and while PASI 100 becomes a realistic target. Using higher cut-off rates of success will lead to a better choice between therapies, but also allow a better "tailormade" treatment for specific patients when determining, through clinical studies, the profile of patients reaching better results.

\section{References}

1. Azizi E, Kushelevsky AP, Avrach W, Schewach-Millet M (1982) Climate therapy 
for psoriasis at the Dead Sea, Israel. Isr J Med Sci 18: 267-270. [Crossref]

2. Harari M, Novack L, Barth J, David M, Friger M, et al. (2007) The percentage of psoriatic patients achieving PASI 75 after one month and remission time after climatotherapy at the Dead Sea. Int J Dermatol (United States) 46: 1087-1091. [Crossref]

3. Katz U, Shoenfeld Y, Zakin V, Sherer Y, Sukenik S (2012) Scientific evidence of the therapeutic effects of Dead Sea treatments: a systematic review. Semin Arthritis Rheum 42: 186-200. [Crossref]

4. Kudish AI, Harari M, Evseev EG (2011) The measurement and analysis of normal incidence solar UVB radiation and its application to the photoclimatherapy protocol for psoriasis at the Dead Sea, Israel. Photochem Photobiol 87: 215-222. [Crossref]

5. Harari M, Shani J (1997) Demographic evaluation of successful anti-psoriatic Climatotherapy at the Dead Sea (Israel) DMZ Clinic. Int J Dermatol (United States) 36: 304-308. [Crossref]

6. Harari M, Czarnowicki T, Fluss R, Ruzicka T, Ingber A (2012) Patients with earlyonset psoriasis achieve better results following Dead Sea Climatotherapy. $J$ Eur Acad Dermatol Venereol 26: 554-559. [Crossref]
7. Kushelevsky AP, Harari M, Kudish AI, Hristakieva E, Ingber A, et al. (1998) Safety of solar phototherapy at the Dead Sea. J Am Acad Dermatol 38: 447-452. [Crossref]

8. Kopel E, Levi A, Harari M, Ruzicka T, Ingber A (2013) Effect of the Dead Sea climatotherapy for psoriasis on quality of life. Isr Med Assoc J 15: 99-102. [Crossref]

9. Gambichler T, Küster W, Kreuter A, Altmeyer P, Hoffmann K (2000) Balneophototherapy--combined treatment of psoriasis vulgaris and atopic dermatitis with salt water baths and artificial ultraviolet radiation. $J$ Eur Acad Dermatol Venereol 14: 425-428. [Crossref]

10. Even-Paz Z (1996) Dermatology at the Dead Sea spas. Isr J Med Sci 32 Suppl: S11-15. [Crossref]

11. Thaci D, Bissonnette R (2015) Is PASI 90 the new PASI 75? Key Opinions in Medicine. Dermatology News 10: 14.

12. Mrowietz U, Kragballe K, Nast A, Reich K (2012) Implementing treatment goals for successful long-term management of psoriasis. J Eur Acad Dermatol Venereol 26 (Suppl. 2): 12-20. [Crossref]

13. Puig L (2015) PASI90 response: the new standard in therapeutic efficacy for psoriasis. J Eur Acad Dermatol Venereol 29: 645-648. [Crossref]

Copyright: (2016 Harari M. This is an open-access article distributed under the terms of the Creative Commons Attribution License, which permits unrestricted use, distribution, and reproduction in any medium, provided the original author and source are credited. 